\title{
Desain Tahan Gempa Jembatan Ngarai Sianok di Bukittinggi, Sumatera Barat - Indonesia
}

\author{
NURUL HAKIM ${ }^{1}$, ENGKON K. KERTAPATI ${ }^{2}$, SUHARA ${ }^{1}$, EDWARD V. M. ${ }^{1}$ \\ 1. PT. Maratama Cipta Mandiri \\ 2. Pusat Penelitian Geologi \\ Email: nurul_nig@yahoo.com
}

\begin{abstract}
ABSTRAK
Jembatan Ngarai sianok dibuat dengan struktur jembatan cable stayed dengan panjang bentang $685 \mathrm{~m}$. Memiliki tinggi pilar 173,5 m. Jembatan ini berada di samping sesar aktif Ngarai sianok sejauh $162 \mathrm{~m}$. Kondisi jembatan yang berada sangat dekat dengan lokasi sumber gempa sesar Ngarai Sianok, membuat analisis bahaya gempa Jembatan Ngarai Sianok mengacu pada perilaku khusus Sesar. Dalam perencaan struktur bangunan, beban gempa rencana untuk analisis respon dinamik digunakan respon spektrum dari karakteristik sesar Ngarai Sianok.

Metoda analisis yang digunakan yaitu metode Deterministic Seismic Hazard Analysis (DSHA) dan Probabilistic Seismic Hazard Analysis (PSHA). Analisis perambatan gelombang menghasilkan rekomendasi respon spektrum desain permukaan untuk periode ulang gempa 950 tahun dengan $P B A=0,973 \mathrm{~g}$. Perbandingan respon spektrum permukaan di lokasi jembatan Ngarai Sianok menunjukkan bahwa hasil analisis perambatan gelombang cendrungan lebih dekat ke Tanah Keras untuk klasifikasi site dari SNI 03-1726-2016 untuk PBA =0,97g.
\end{abstract}

Kata kunci: cable-stayed, sesar, ground motion, respon spektrum.

\begin{abstract}
Ngarai Sianok Bridge is made with a Cable Stayed bridge structure with a span length of $685 \mathrm{~m}$. Has a pillar height of $173.5 \mathrm{~m}$. This bridge is beside the active canyon sianok as far as $162 \mathrm{~m}$. The condition of the bridge which is very close to the location of the Ngarai Sianok fault source, made an earthquake hazard analysis of the Ngarai Sianok Bridge referring to the special behavior of Fault. In planning the structure of the building, the earthquake load planned to analyze the dynamic response used a spectra response from the characteristic character of the Ngarai Sianok fault.

The analytical method used is the Deterministic Seismic Hazard Analysis (DSHA) method and Probabilistic Seismic Hazard Analysis (PSHA). Wave propagation analysis results in a recommendation of a surface design response for the return period of a 950 year earthquake with $P B A=0.973 \mathrm{~g}$. Comparison of the surface spectrum response at the Ngarai Sianok bridge location shows that the results of the wave propagation analysis tend to be closer to hard soil for the site classification of SNI 03-1726-2016 for $P B A=0.97 \mathrm{~g}$.
\end{abstract}

Keywords: cable stayed, fault, ground motion, spectra response. 


\section{PENDAhuluan}

Merespon pertumbuhan ekonomi masyarakat di segala bidang yang bermuara kepada kemakmuran masyarakat khususnya di Kota Bukittinggi - Sumatera Barat. Pembangunan jembatan yang melintasi Lembah Ngarai Sianok perlu segera dilakukan. Jembatan Ngarai Sianok memiliki struktur desain jembatan cable stayed dengan panjang bentang $685 \mathrm{~m}$. dengan tinggi pilar $173,5 \mathrm{~m}$. Jembatan ini akan menjadi jembatan cable stayed tertinggi di Indonesia. Tampak memanjang dan detail jembatan dapat dilihat pada Gambar 1 dan Gambar 2.

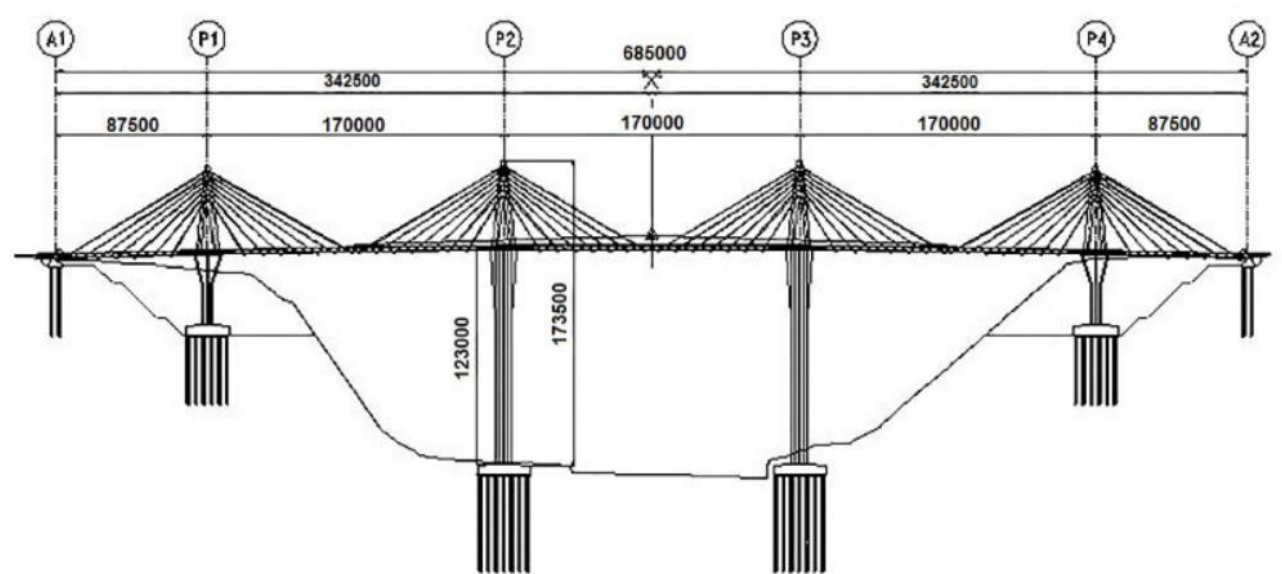

Gambar 1. Tampak memanjang rencana Jembatan Ngarai Sianok
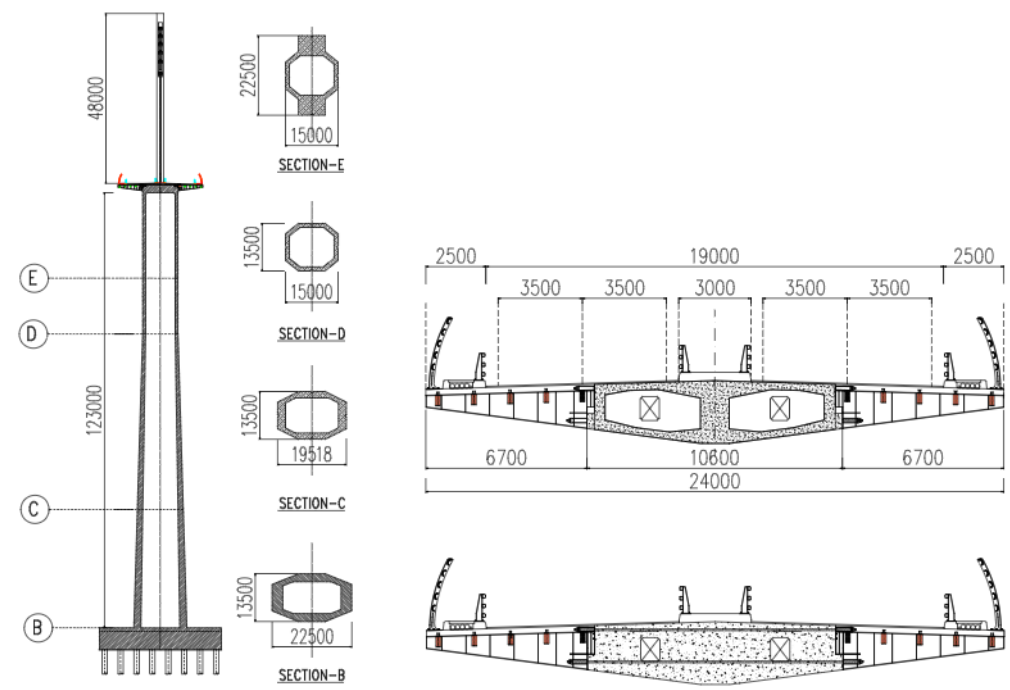

Gambar 2. Dimensi pilar dan lantai rencana Jembatan Ngarai Sianok

Mengingat posisinya, lokasi rencana Jembatan Ngarai Sianok-Bukittinggi ini terletak di daerah kondisi geologi yang relatif tidak komplek akan tetapi dikelilingi oleh sumber-sumber gempa, oleh karena itu maka jembatan ini harus aman terhadap ancaman gempa bumi dan seyogyanya jembatan tersebut secara prinsif harus kokoh dari ancaman gaya gempa bumi yang akan menggoncangnya. Sehingga dengan demikian, untuk keselamatan bangunan Jembatan Ngarai Sianok tersebut akan dilakukan kajian geologi, sejarah kegempaan, pengumpulan data kegempaan sekunder, karakterisasi sumber-sumber gempa bumi, analisis bahaya gempa bumi dan analisis efek dari kondisi tanah lokal. Maka dari itu, obyek utama 
dari studi geologi ini adalah menentukan atau mengevaluasi kondisi geologi untuk berkaitan dengan Level Bahaya Gempa Bumi dan Pengaruh Kondisi Tanah Lokal untuk Rencana Jembatan Ngarai Sianok-Bukittinggi-Sumatera Barat seperti pada Gambar 3.

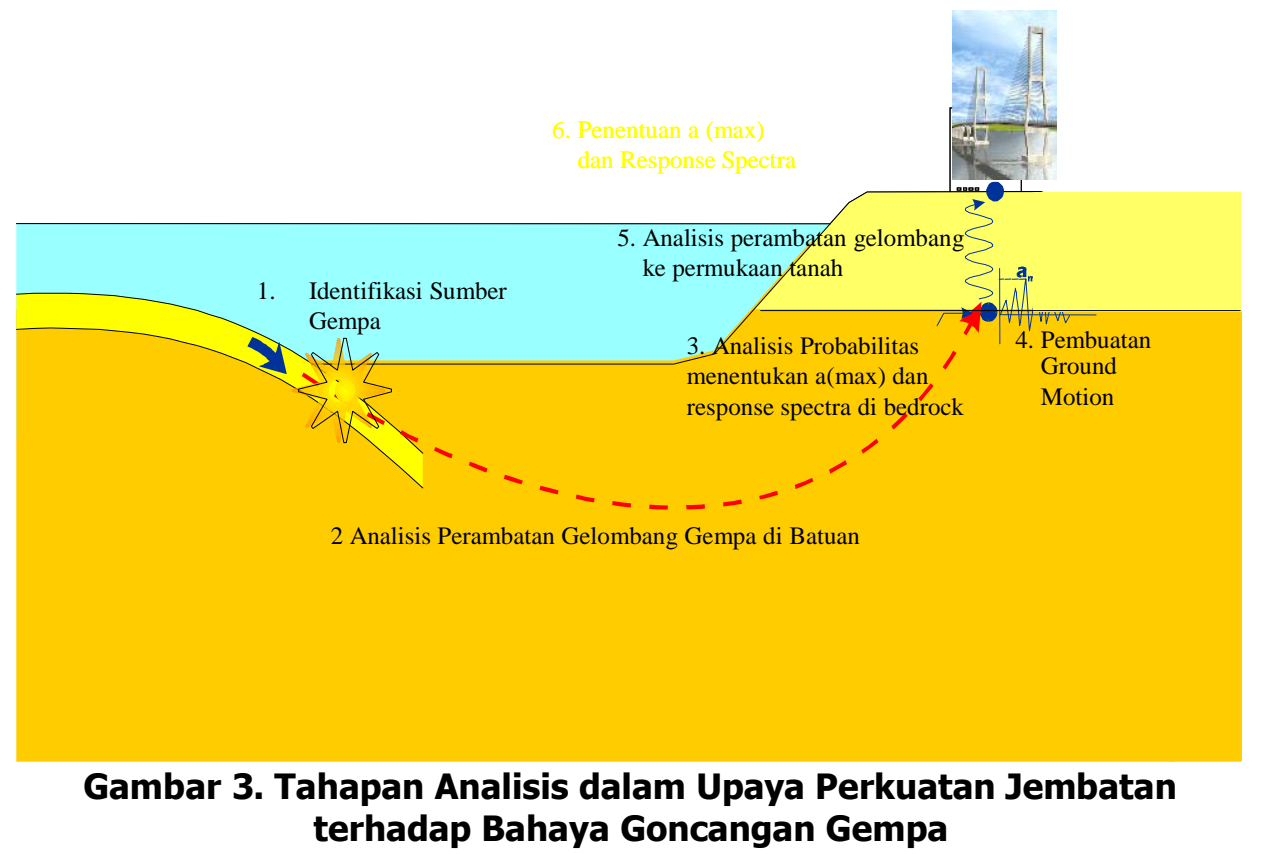

Dari hasil penelitian dan kajian geologi dan aspek sesar aktif, jelas terlihat bahwa rencana Jembatan Ngarai Sianok terletak sekitar 162 meter di sebelah timur segmen sesar aktif Ngarai Sianok. Namun walaupun demikian, berdasarkan karakteristik sesar/sumber dekat/near field sources dari penelitian dan kajian geologi tersebut, dan berdasarkan rekomendasi badan internasional (UBC 1997 dan IBC 2003,serta IEEE 693- 205), tidak ada hambatan bagi pembangunan Jembatan Ngarai Sianok untuk dibangun pada lokasi yang diusulkan yaitu di lembah Ngarai Sianok.

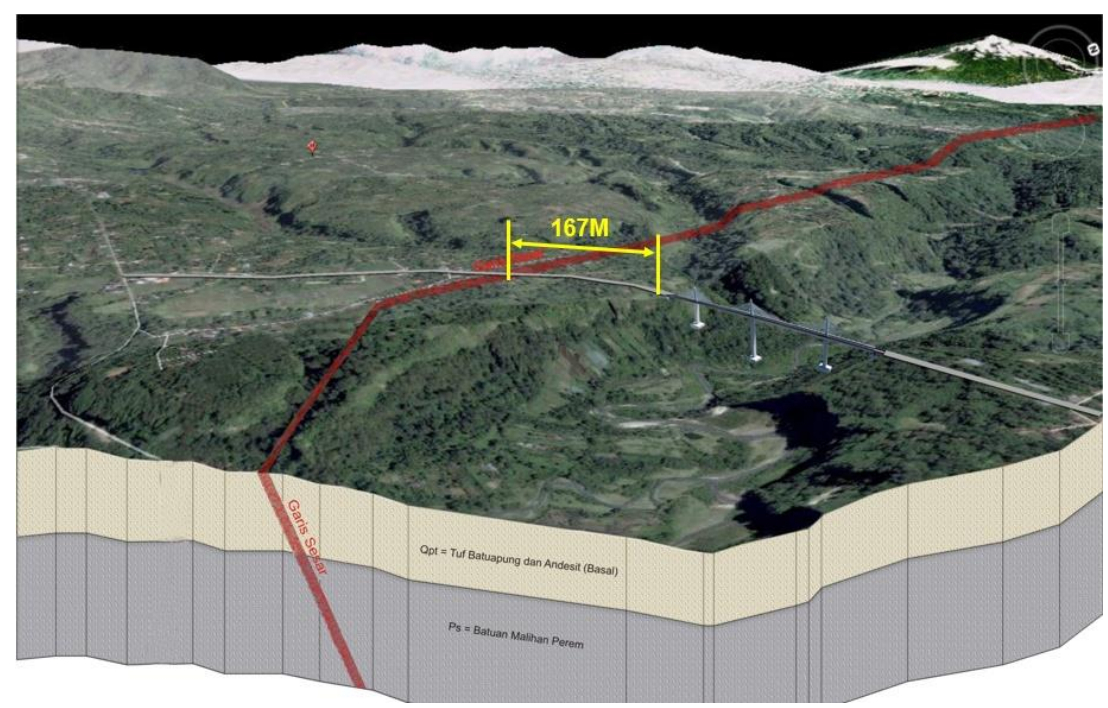

Gambar 4. Posisi sesar aktif Ngarai Sianok terhadap lokasi rencana Jembatan Ngarai Sianok 


\section{ANALISIS BAHAYA GEMPA}

Fenomena gempa bumi yang terjadi di permukaan tanah adalah suatu gerakan tiba-tiba yang parameter kekuatannya dinyatakan dalam percepatan, kecepatan dan simpangan. Secara garis besar, tingkat kerusakan yang mungkin terjadi tergantung dari besaran dan kedalaman, serta lama getaran gempa, kondisi geologi dan geotektonik lokasi bangunan, dan percepatan tanah di lokasi bangunan akibat dari getaran suatu gempa bumi serta kualitas bangunan itu sendiri.

Oleh karena itu, salah satu cara untuk bisa mengantisipasi efek primer dari gempa adalah mendesain struktur bangunan agar tahan terhadap goncangan tersebut. Dalam perencaan struktur bangunan, beban gempa rencana untuk analisa respon dinamik biasanya digunakan Respon Spektrum dan $a_{\text {maks }}$ permukaan. Untuk mendapatkan nilai respon spektrum dan $a_{\text {maks }}$ permukaan ada tahapan analisis yang harus dilalui dimana tahapannya adalah:

1. Identifikasi model sumber gempa.

2. Analisa perambatan gelombang gempa, model fungsi atenuasi.

3. Analisa probabilitas, penentuan $a_{m a k s}$ di batuan dasar.

4. Penentuan ground motion.

5. Analisa perambatan gelombang di deposit tanah.

6. Pembuatan respon spektrum rencana dan $a_{\text {maks }}$ permukaan tanah.

Fenomena gempa dapat digambarkan sebagai pelepasan energi oleh batuan bumi yang mengalami stress (baik regangan maupun tekanan) setelah mengalami akumulasi dalam jangka waktu tertentu sesuai dengan sifat fisik batuan buminya. Semakin tinggi kekuatan batuan dalam menahan stress semakin besar pula energi yang dilepaskan. Dengan kata lain; semakin besar periode ulang suatu gempa semakin besar pula magnitude gempa yang akan terjadi, dan semakin besar magnitude gempa makin besar pula percepatan tanah yang terjadi di suatu tempat; sehingga tingkat risiko bangunan terhadap gempa bumi bisa terkait dengan periode ulang gempa bumi.

Analisa hazard gempa (seismic hazard analysis) sering dipakai untuk menentukan tingkat pembebanan yang mungkin akan terjadi pada suatu tempat. Terdapat 2 (dua) metode perhitungan yang bisa dikerjakan; yaitu Deterministic Seismic Hazard Analysis (DSHA) yang akan menjawab untuk mengetahui perilaku gerakan tanah jika gempa terjadi (Frankel, 1996), sementara Probabilistic Seismic Hazard Analysis (PSHA) digunakan untuk menganalisis berapakah probabilitas melebihi gerakan tanah yang ditentukan selama periode waktu tertentu atau apa gerakan tanah yang memiliki probabilitas tertentu untuk dilampaui selama periode waktu tertentu (Frankel, 1996).

Paramater-parameter data paleo-seismik, seismik, geologi-geotektonik sangat diperlukan di dalam karakterisasi zona sumber gempa sebagai potensi seismogenik di sekitar Lokasi rencana Jembatan Ngarai Sianok Bukittinggi. Pada umumnya, kewenangan spesifik geologi tertuju kepada fitur-fitur tektonik, seperti struktur sesar yang dapat menerangkan dimana gempa bumi telah terjadi atau kejadian gempa masa lalu. Oleh karena itu, hal tersebut sangat diperlukan untuk pengembangan analisis deterministik ataupun analisis probabilistik goncangan gempa. Berdasarkan pada karakteristik tektonik, geologi, seismologi berikut aspek geofisika yang diketahui ataupun tidak diketahui, maka daerah lokasi rencana Jembatan Ngarai Sianok-Bukittinggi dibagi ke dalam beberapa zona-zona sumber gempa dengan radius kira-kira $300 \mathrm{~km}$. Gempa-gempa berjarak lebih jauh dari jarak tersebut pada umumnya tidak merusakan bangunan. Sumber gempa dan pemodelannya berdasarkan hasil rekomendasi dapat dilihat pada Tabel $\mathbf{1}$ dan Tabel $\mathbf{2}$ berikut: 
Tabel 1. Estimasi Karakteristik Potensi Sumber Gempa Patahan ( Fau/t) untuk Jembatan Ngarai Sianok

\begin{tabular}{cccccccc}
\hline No & Fault Name & $\begin{array}{c}\text { Slip-Rate } \\
{[\mathbf{m m} / \mathbf{y r}]}\end{array}$ & Sense & $\begin{array}{c}\text { Dip } \\
{[\mathbf{d e g}]}\end{array}$ & $\begin{array}{c}\text { Top } \\
{[\mathbf{k m}]}\end{array}$ & $\begin{array}{c}\text { Bottom } \\
{[\mathbf{k m}]}\end{array}$ & $\boldsymbol{M}_{\text {maks }}$ Desain \\
\hline $\mathbf{1}$ & Renun & 27 & Strike-slip & 90 & 3 & 20 & 7,8 \\
\hline $\mathbf{2}$ & Toru & 24 & Strike-slip & 90 & 3 & 20 & 7,4 \\
\hline $\mathbf{3}$ & Angkola & 19 & Strike-slip & 90 & 3 & 20 & 7,6 \\
\hline $\mathbf{4}$ & Barumun & 19 & Strike-slip & 90 & 3 & 20 & 7,5 \\
\hline $\mathbf{5}$ & Sumpur & 19 & Strike-slip & 90 & 3 & 20 & 6,9 \\
\hline $\mathbf{6}$ & Sianok & 19 & Strike-slip & 90 & 3 & 20 & 7,3 \\
\hline $\mathbf{7}$ & Sumani & 19 & Strike-slip & 90 & 3 & 20 & 7,2 \\
\hline $\mathbf{8}$ & Suliti & 19 & Strike-slip & 90 & 3 & 20 & 7,4 \\
\hline $\mathbf{9}$ & Siulak & 11 & Strike-slip & 90 & 3 & 20 & 7,2 \\
\hline $\mathbf{1 0}$ & Dikit & 11 & Strike-slip & 90 & 3 & 20 & 7,2 \\
\hline $\mathbf{1 1}$ & Ketaun & 11 & Strike-slip & 90 & 3 & 20 & 7,3 \\
\hline $\mathbf{1 2}$ & Musi & 11 & Strike-slip & 90 & 3 & 20 & 7,2 \\
\hline $\mathbf{1 3}$ & Manna & 11 & Strike-slip & 90 & 3 & 20 & 7,3 \\
\hline $\mathbf{1 4}$ & Kumering & 11 & Strike-slip & 90 & 3 & 20 & 7,6 \\
\hline
\end{tabular}

Tabel 2. Estimasi Karakteristik Potensi Sumber Gempa Background untuk Jembatan Ngarai Sianok

\begin{tabular}{|c|c|c|c|c|c|c|}
\hline \multirow{2}{*}{$\begin{array}{l}\text { Background } \\
\text { Condition }\end{array}$} & \multirow{2}{*}{\multicolumn{2}{|c|}{$\begin{array}{c}\text { Depth of } \\
\text { Background } \\
{[\mathrm{km}]}\end{array}$}} & \multicolumn{2}{|c|}{ Magnitude } & \multirow{2}{*}{ b-value } & \multirow{2}{*}{ a-value } \\
\hline & & & Minimum & Maksimum & & \\
\hline \multirow{5}{*}{ Shallow Background } & 0 & -10 & 5 & 6,5 & 1 & 4,772 \\
\hline & 10 & -20 & 5 & 6,5 & 1 & 4,795 \\
\hline & 20 & $-\quad 30$ & 5 & 6,5 & 1 & 5,011 \\
\hline & 30 & -40 & 5 & 6,5 & 1 & 5,702 \\
\hline & 40 & -50 & 5 & 6,5 & 1 & 5,094 \\
\hline \multirow{5}{*}{$\begin{array}{c}\text { Intermediate- } \\
\text { Deep Background }\end{array}$} & 50 & -75 & 5 & 7,2 & 1 & 5,147 \\
\hline & 75 & -100 & 5 & 7,2 & 1 & 5,224 \\
\hline & 100 & -150 & 5 & 7,2 & 1 & 5,355 \\
\hline & 150 & -200 & 5 & 7,2 & 1 & 5,152 \\
\hline & 200 & -300 & 5 & 7,2 & 1 & 5,132 \\
\hline
\end{tabular}

Tabel 3. Estimasi Karakteristik Potensi Sumber Gempa Subduksi (Subduction) untuk Jembatan Ngarai Sianok

\begin{tabular}{|c|c|c|c|c|c|c|c|}
\hline \multirow{2}{*}{ No } & \multirow{2}{*}{$\begin{array}{c}\text { Suduction } \\
\text { Name }\end{array}$} & \multirow{2}{*}{$M_{\text {maks }}$ History } & \multirow{2}{*}{ b-value } & \multirow{2}{*}{ a-value } & \multicolumn{2}{|c|}{$\begin{array}{c}M_{\text {maks }} \\
\text { (Desain) }\end{array}$} & \multirow{2}{*}{$\begin{array}{l}\text { Slip-Rate } \\
\text { [mm/yr] }\end{array}$} \\
\hline & & & & & $G R$ & Char & \\
\hline 1 & Mid-1 Sumatera & $8,7(28-03-2005)$ & 0,878 & 4,71 & 8,7 & 8,7 & 60 \\
\hline 2 & Mid-2 Sumatera & $8,5(12-09-2007)$ & 0,97 & 5,35 & 8,5 & 8,5 & 60 \\
\hline
\end{tabular}

\subsection{Analisis Probabilistik Seismic Hazard Analisis}

Tiga level hazard dihitung, yaitu $10 \%$ in 50 years probability of exceedance (RP 475 tahun), $5 \%$ in 50 years probability of exceedance (RP 975 tahun) dan $2 \%$ in 50 years probability of exceedance (RP 2475 tahun) dengan referensi base rock untuk lokasi rencana Jembatan Ngarai Sianok. Uniform Hazard Spectra (UHS) dan hasil deagregasi untuk level hazard RP 475, dan RP 975 tahun juga dihitung. Gambar 5 dan Tabel 4 memperlihatkan Uniform Hazard Spectra (UHS) dari site Jembatan Ngarai Sianok. 


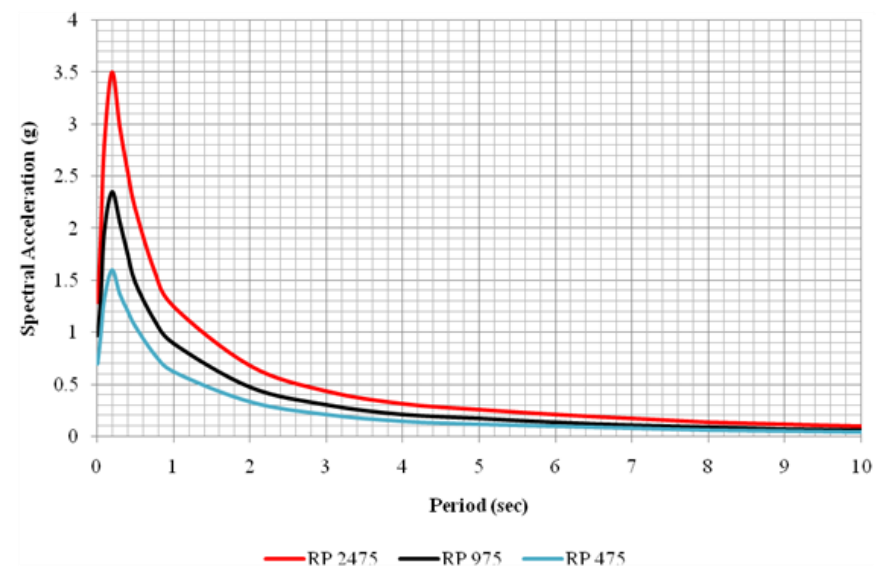

Gambar 5. UHS lokasi Jembatan Ngarai Sianok

Tabel 4. Digitasi UHS untuk Periode PBA 0,2 detik dan 1,0 detik disetiap Level Hazard

\begin{tabular}{cccc}
\hline \multirow{2}{*}{ Periode } & \multicolumn{3}{c}{ Acceleration [g] } \\
\cline { 2 - 4 } & RP 475 & RP 975 & RP 2475 \\
\cline { 2 - 4 } & PSHA 2013 & PSHA 2013 & PSHA 2013 \\
\hline PBA & 0.690 & 0.973 & 1.289 \\
\hline 0,2 detik & 1.603 & 2.349 & 3.500 \\
\hline 1,0 detik & 0.620 & 0.893 & 1.254 \\
\hline
\end{tabular}

Hazard curve hasil dari PSHA untuk periode PBA 0,2 dan 1,0 detik dapat dilihat pada Gambar 6 dan Gambar 7 yang memperlihatkan hasil De-agregasi di periode 0,2 detik dan 1,0 detik untuk periode ulang 975 tahun.

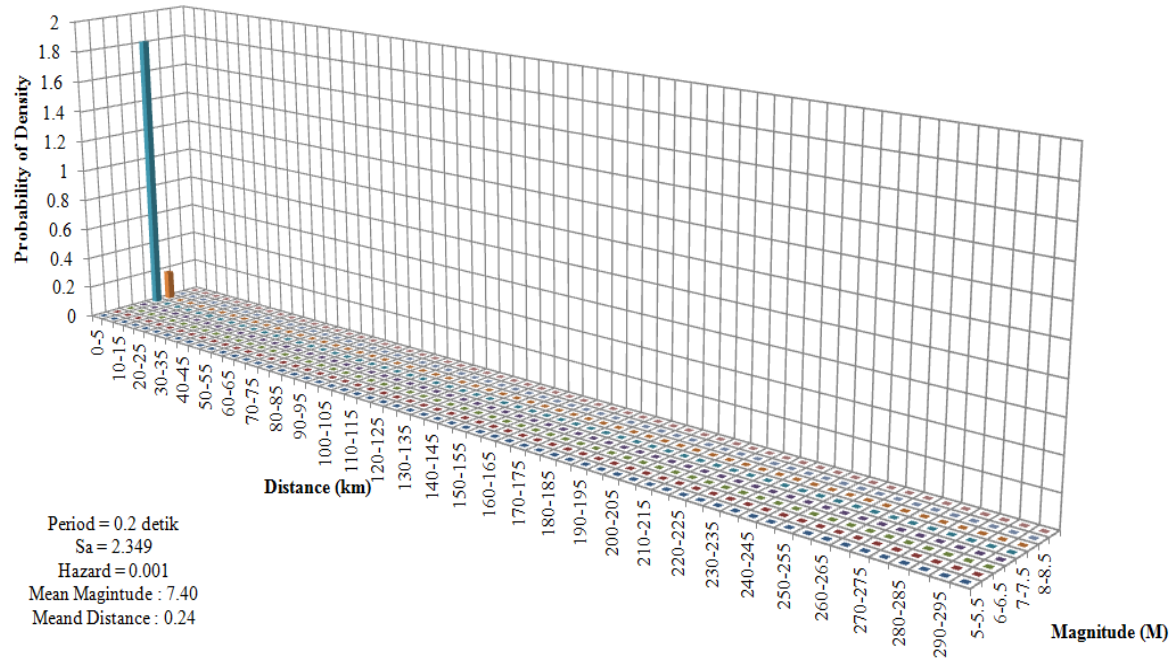

Gambar 6. De-agregasi $T=0,2$ detik untuk RP 975 tahun 


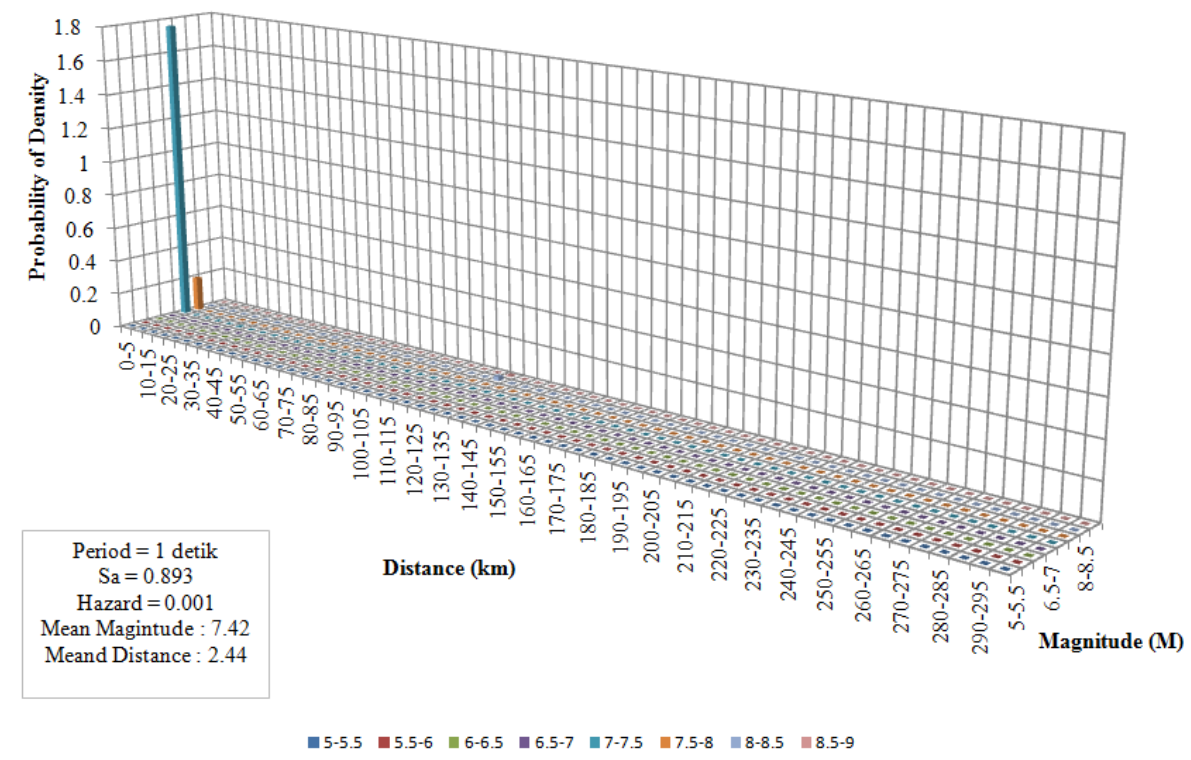

Gambar 7. De-agregasi $T=1,0$ detik untuk RP 975 tahun

Controlling magintude dan distance dari hasil De-agregasi pada periode 0,2 dan 1,0 detik untuk periode ulang 975 tahun dapat dilihat pada Tabel 5 dan Tabel 6.

Tabel 5. Controlling Magnitude dan Distance (M,R) Hasil De-agregasi di Periode 0,2 detik RP 975

\begin{tabular}{ccc}
\hline Mekanisme Gempa & $\boldsymbol{M}$ & $\boldsymbol{R}[\mathbf{k m}]$ \\
\hline Inter-Plate (Megathrust) & 8,60 & 121,59 \\
\hline $\begin{array}{c}\text { Intra-Plate } \\
\text { (Benioff) }\end{array}$ & 7,07 & 95,35 \\
\hline Shallow Crustal & 7,40 & 0,1 \\
\hline Shallow Background & 6,34 & 69,17 \\
\hline
\end{tabular}

Tabel 6. Controlling Magnitude dan Distance $(\mathrm{M}, \mathrm{R})$ Hasil De-agregasi di Periode 1,0 detik RP 975

\begin{tabular}{ccc}
\hline Mekanisme Gempa & $\boldsymbol{M}$ & $\boldsymbol{R}[\mathbf{k m}]$ \\
\hline Inter-Plate (Megathrust) & 8,47 & 124,96 \\
\hline $\begin{array}{c}\text { Intra-Plate } \\
\text { (Benioff) }\end{array}$ & 7,12 & 95,40 \\
\hline Shallow Crustal & 7,40 & 0,1 \\
\hline Shallow Background & 6,44 & 52,96 \\
\hline
\end{tabular}

Untuk probabilitas periode ulang 975 tahun akan dihasilkan input motion sintetik. Untuk pembuatan input motion sintetik dibutuhkan target spektrum pada periode pendek 0,2 detik dan panjang 1,0 detik. Target spektrum dikembangkan berdasarkan penskalaan dengan metode Conditional Mean Spectrum (Baker, 2011) untuk setiap periode pendek 0,2 detik dan periode panjang 1,0 detik. Target spektrum juga merepresentasikan dari masing-masing sumber gempa. Gambar 8 dan Gambar 9 memperlihatkan target spektrum dari masingmasing periode. 


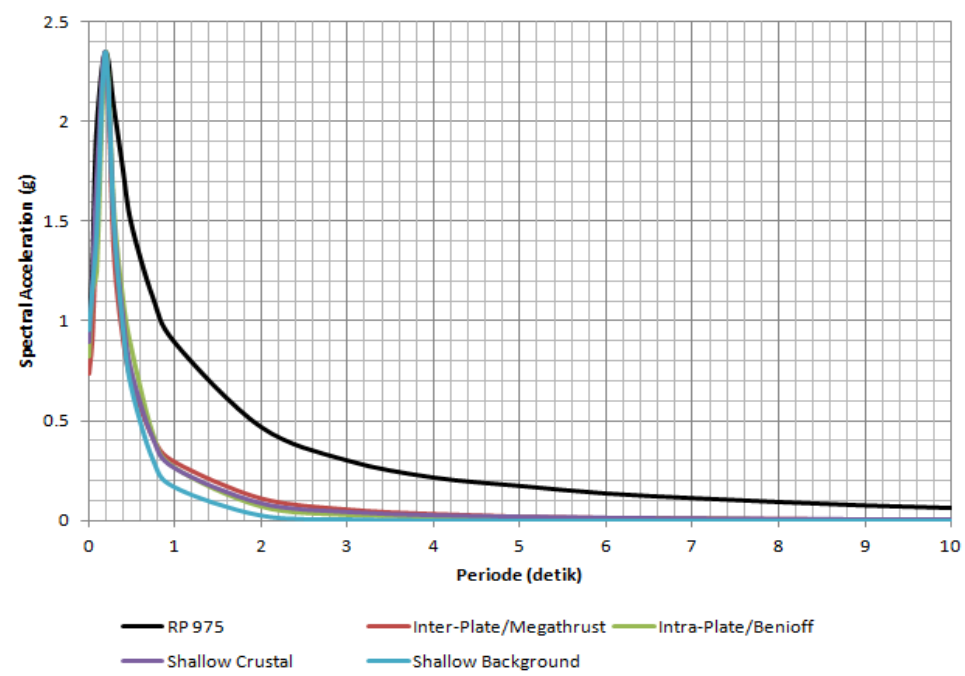

Gambar 8. Target sektrum untuk periode 0,2 detik RP 975

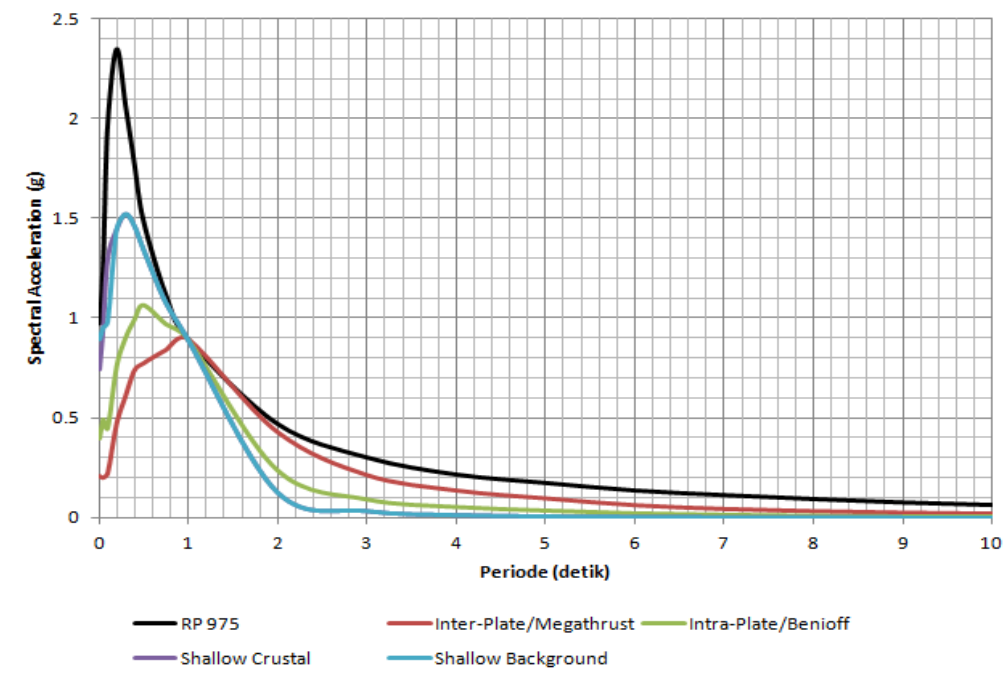

Gambar 9. Target spektrum untuk periode 1,0 detik RP 975

Berdasarkan target spektrum pada Gambar 8 dan Gambar 9 di atas, input motion sintetik dibuat dengan menggunakan metode RSPMATCH99. Lima input motion digunakan untuk masing-masing periode dan masing-masing periode ulang dicocokan.

\subsection{Analisis Perambatan Gelombang}

Penyelidikan tanah di lokasi rencana Jembatan Ngarai Sianok dilakukan sebanyak 8 (delapan) titik dengan kedalaman maksimum sampai 40 meter. Layout titik-titik pengeboran ditunjukkan seperti pada Gambar 10. Untuk area tebing barat dilakukan 3 (tiga) titik bor dalam di BH-01 sampai BH-03, di are lembah dilakukan 2 (dua) titik bor dalam di BH-04 dan $\mathrm{BH}-05$, dan area tebing timur (arah Bukit Tinggi) dilakukan 3 (tiga) titik bor dalam di $\mathrm{BH}-06$ sampai BH-08. Seismic Downhole Test (SDT) dilakukan pada semua lubang bor atau sebanyak 8 (delapan) titik bor. 


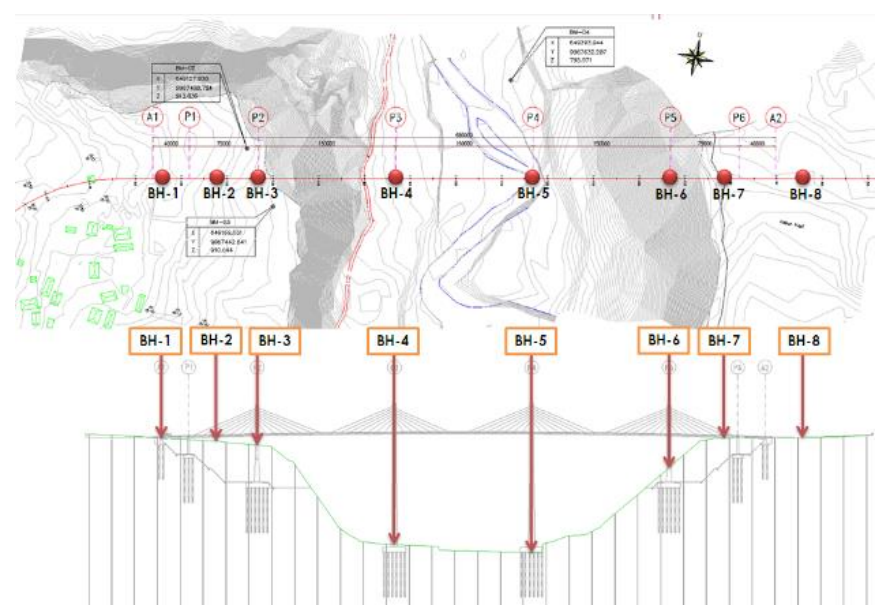

Gambar 10. Sket lokasi titik-titik bor

Secara umum, untuk area tebing barat, lapisan tanah permukaan dengan ketebalan 4-10 meter merupakan lempung kapasiran dan pasir kelempungan dengan kosistensi medium stiff to very stiff, dengan N-SPT = 7-19. Lapisan kedua pada kedalaman 10-15 meter merupakan tuffaceus sand, very dense, dengan N-SPT $=45-73$. Lapisan ketiga pada kedalaman 15 meter sampai akhir pengeboran merupakan tuffaceus sand, very dense, dengan N-SPT >75.

Untuk area lembah, lapisan tanah permukaan dengan ketebalan 2-5 meter merupakan lempung kapasiran dan pasir kelempungan dengan kosistensi very stiff, dengan N-SPT = 21-24. Lapisan kedua pada kedalaman 5-15 meter merupakan tuffaceus sand, very dense, dengan N-SPT $=38-67$. Lapisan ketiga pada kedalaman 15 meter sampai akhir pengeboran merupakan tuffaceus sand, very dense, dengan N-SPT >75.

Sedangkan berdasarkan data Seismic Downhole Test, lapisan pertama pada kedaman 0-8 meter merupakan Tanah Lunak sampai Tanah Sedang dengan $V_{s}$ (kecepatan gelombang geser tanah) $=81-338 \mathrm{~m} / \mathrm{s}$. Lapisan kedua pada kedalaman 8-35 meter (akhir pengeboran) merupakan Tanah Sedang sampai Tanah Keras dengan $V_{s}=214-550 \mathrm{~m} / \mathrm{s}$ (dengan selingan lensa pasir lepas).

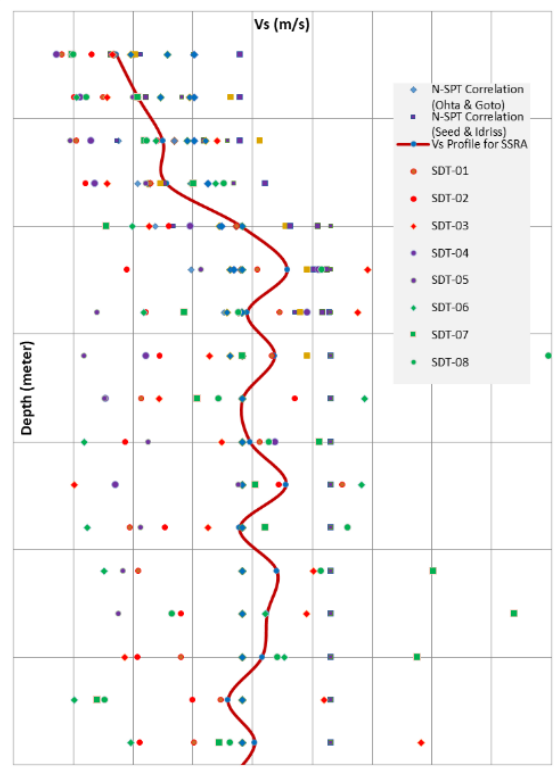

Gambar 11. Kecepatan gelombang geser sebagai fungsi kedalaman untuk lokasi jembatan Ngarai Sianok mengacu kepada data N-SPT dan Seismic Downhole Test

RekaRacana: Jurnal Teknik Sipil - 27 
Selanjutnya, untuk keperluan analisis perambatan gelombang dari batuan dasar ke pemukaan tanah, parameter kecepatan gelombang geser tanah $\left(V_{s}\right)$ ditentukan berdasarkan data korelasi N-SPT dan SDT hasil pengukuran lapangan pada lokasi rencana jembatan. Batuan dasar (baserock) dengan kecepatan gelombang geser lebih dari $V_{s}=760 \mathrm{~m} / \mathrm{s}$ diasumsikan berada pada kedalaman 100 meter. Gambar 11 menunjukkan data kecepatan gelombang geser berdasarkan hasil korelasi dari N-SPT dan SDT, serta rekomendasi $V_{S}$ desain sebagai fungsi kedalaman untuk lokasi jembatan Ngarai Sianok.

Analisis respon site-spesifik (Site Specific Response Analysis, SSRA) dilakukan dengan program komputer NERA untuk untuk PBA $=0,973 \mathrm{~g}$ untuk periode ulang 950 tahun berdasarkan kondisi spesifik profil kecepatan gelombang geser di lokasi rencana jembatan Ngarai Sianok.

Hasil analisis untuk periode ulang gempa 950 tahun yang menunjukkan respon spektrum permukaan hasil analisis perambatan gelombang waktu berdasarkan profil kecepatan gelombang geser $\left(V_{S}\right)$ tanah rata-rata dari hasil korelasi N-SPT rangkuman respon spektrum desain dalam tabulasi yang menunjukkan percepatan gempa sebagai fungsi periode (detik) untuk PBA $=0,973 g$, ditampilkan pada Tabel 7.

Tabel 7. Rekomendasi Respon Spektrum Desain yang Sesuai pada Periode Rendah dan Periode Tinggi [detik], untuk Periode Ulang Gempa 950 tahun, PBA = 0,73g

\begin{tabular}{|c|c|}
\hline \multicolumn{2}{|c|}{$\begin{array}{c}\text { PBA }=0,973 g \\
T_{s}=0,60 \text { sec, } C_{a}=0,80 g, \\
C_{v}=1,20\end{array}$} \\
\hline$T$ [detik] & $S_{a}$-desain $[g]$ \\
\hline 0,00 & 0,80000 \\
\hline 0,12 & 2,00000 \\
\hline 0,60 & 2,00000 \\
\hline 1,00 & 1,20000 \\
\hline 1,20 & 1,00000 \\
\hline 1,50 & 0,80000 \\
\hline 2,00 & 0,60000 \\
\hline 2,50 & 0,48000 \\
\hline 3,00 & 0,40000 \\
\hline 3,50 & 0,34286 \\
\hline 4,00 & 0,30000 \\
\hline 4,50 & 0,26667 \\
\hline 5,00 & 0,24000 \\
\hline 6,00 & 0,20000 \\
\hline 7,00 & 0,17143 \\
\hline 8,00 & 0,15000 \\
\hline 9,00 & 0,13333 \\
\hline 10,00 & 0,12000 \\
\hline
\end{tabular}

Selanjutnya respon sspektrum desain yang dikembangan dari hasil analisis perambatan gelombang untuk periode ulang gempa 950 tahun dengan PBA $=0,963 \mathrm{~g}$ mengacu kepada hasil PSHA di lokasi jembatan Ngarai Sianok dibandingkan dengan respon spektrum SNI 03-1726-2016 untuk periode ulang bangunan 0-4 detik, seperti ditunjukkan pada Gambar 12. Perbandingan respon spektrum permukaan menunjukkan bahwa hasil analisis 
perambatan gelombang dengan PBA $=0,973 g$ (SSRA, 2013) ini berada diantara spektrum Tanah Sedang (SD) dan Tanah Keras (SE) dengan kecenderungan lebih dekat ke Tanah Keras (SC) untuk klasifikasi site dari SNI-1726-20116 dengan PBA $=0,970 \mathrm{~g}$.

Mempertimbangkan kondisi spesifik di lokasi jembatan Ngarai Sianok yang berada pada kondisi antara Tanah Sedang (SD) sampai Tanah Keras (SC) dan mengacu kepada hasil seismic hazard di Bukit Tinggi untuk periode ulang 950 tahun dengan PBA =0,973 g, maka respon spektrum desain jembatan Ngarai Sianok direkomendasikan mengacu kepada hasil SSRA ini yang telah mempertimbangkan 7 (tujuh) input motion untuk setiap periode yang merepresentasikan potensi gempa subduksi dan shallow crustal.

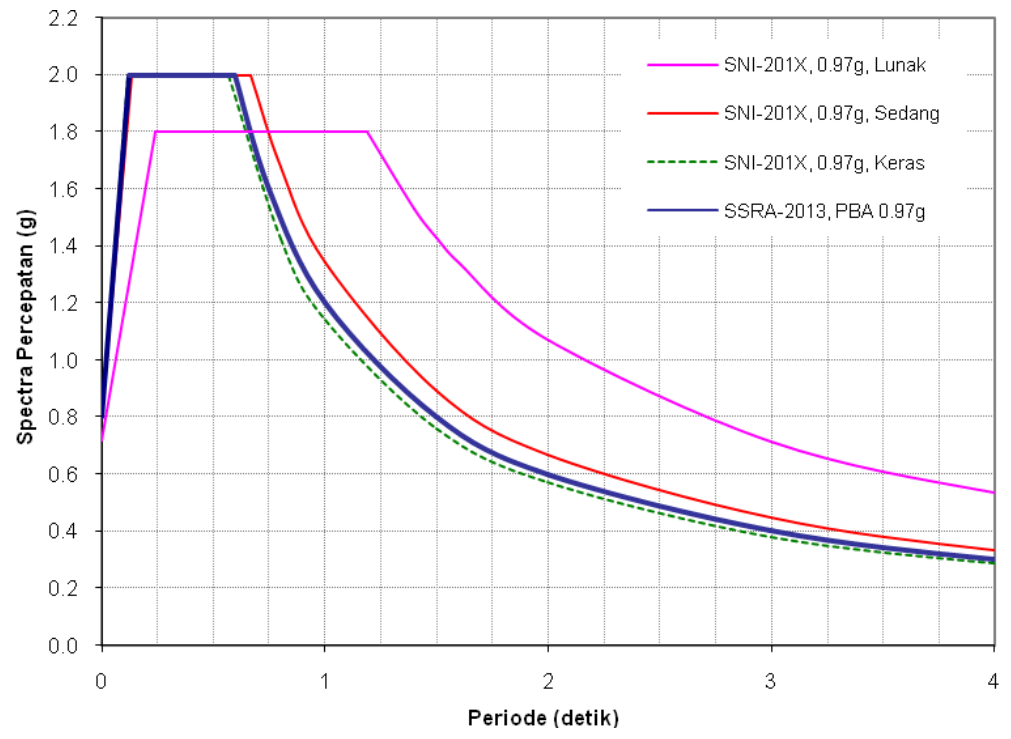

Gambar 12. Perbandingan respon spektrum desain hasil SSRA dengan PBA $=0,973 g$
dibandingkan dengan SNI-1726-2016 untuk PBA $=0,970 g$

\section{KESIMPULAN DAN REKOMENDASI}

Berdasarkan hasil evaluasi potensi gempa dan analisis respon site-spesifik untuk Jembatan Ngarai Sianok, dapat disimpulkan dan direkomendasikan hal-hal sebagai berikut:

1. Target spektrum telah memepertimbangkan sumber-sumber gempa subduksi di sekitar Bukit Tinggi dan shallow crustal faults dalam radius $500 \mathrm{~km}$ dari lokasi jembatan Ngarai Sianok. Target spektrum dikembangkan untuk PBA $=0,973 \mathrm{~g}$ untuk periode ulang gempa 975 tahun berdasarkan hasil analisis sesuai input parameter gempa yang sudah ada sebelumnya untuk area Sumatra Barat, dengan menggunakan fungsi atenuasi yang sesuai dan tersedia pada program komputer EZ-FRISK.

2. Untuk gempa dengan kemungkinan periode ulang 950 tahun, selanjutnya dikembangkan beberapa input motion berdasarkan target spektrum dari gempa subduksi dan juga gempa shallow crustal yang diskalakan pada $T=0,2$ detik dan $T=1,0$ detik. Metode spectral matching dari beberapa data rekaman kejadian gempa digunakan untuk merekomendasikan 7 (tujuh) input motion untuk masing-masing periode yang merepresentasikan potensi gempa-gempa subduksi dan shallow crustal.

3. Seismic Downhole Test (SDT) pada 8 (delapan) lokasi digunakan untuk input dalam membuat profil kecepatan gelombang geser lapisan tanah sampai kedalaman 40 meter. Parameter kecepatan gelombang geser tanah tersebut juga diverifikasi berdasarkan pendekatan korelasi empiris nilai SPT dan data-data lainnya dari data pengeboran. 
4. Mengacu kepada klasifikasi site SNI-1726-2002 \& UBC-1997, maka lapisan tanah di rencana lokasi jembatan Ngarai Sianok cendrung diklasifikasikan sebagai Tanah Sedang sampai Tanah Keras.

5. Analisis perambatan gelombang telah menghasilkan rekomendasi respon spektrum desain permukaan untuk periode ulang gempa 950 tahun dengan PBA $=0,973 \mathrm{~g}$. Rekomendasi respon spektrum desain hasil analisis perambatan gelombang ini selanjutnya dibandingkan dengan respon spektrum SNI-1726-2016 untuk rentang periode 0-4 detik. Perbandingan spektrum permukaan di lokasi jembatan Ngarai Sianok menunjukkan bahwa hasil analisis perambatan gelombang ini (SSRA, 2013) ini berada diantara spektrumTanah Sedang $(S D)$ dan Tanah Keras $(S E)$ dengan kecendrungan lebih dekat ke Tanah Keras $(S C)$ untuk klasifikasi site dari SNI 03-1726-2016 untuk PBA $=0,97 g$.

\section{DAFTAR RUJUKAN}

Baker, J. (2011). Conditional Mean Spectrum: Tool for Ground-Motion Selection. Journal of Structural Engineering , 3(137), 322-331.

Frankel, A. (1996). How can seismic hazard around the New Madrid Seismic Zone be similar to that in California? Seismol. Res.Lett. (_), 575-586. 